\title{
OJCOWIE KOŚCIOŁA \\ W PISMACH TEOLOGICZNO-MORALNYCH \\ MIKOŁAJA Z MOŚCISK \\ (1559-1632)
}

Rozumiejąc przez Tradycje głównle całość przekazu objawlenia - dziezach Ojcón Kościoła, zaraz na wstępie nalezy stwierdzió, zo argumentaoja czerpana z tego źródła, podobnto jak 1 z Pisma ó.. jest bardzo skaba 1 minimalnie wykorzystana w dziezach teologicznych, a takze 1 teologiczno-moralnych XVI 1 XVII rieku. W ́́wczesnej polskiej myśl1 teologlcznej zaumaza się dość zróznioowana postawe poszczególnych autorów odnó́nie do walorów pism 0jców Kośc1o1a. Tak, np. Szymon Stan1sław Makowsk1/ok. 1612-1683/ z upodobaniem 1 bardzo ozesto posługiwał s1e tego typu argumentacja, gromadząo bardzo liczne teksty. patrystyczne,któryoh myśl1 szeroko nykoxzystywal $w$ anal1zie poszczególnych kwest11 teologloznych. Jego egzegeza Plsma $B_{w}$. oparta była rónniez $w$ duzej mierze na patrystyce ${ }^{1}$. Inny przedstawiciel Akademil Krakowskiej, Adam z Opatowa/1574-1647/ m1ał także świadomość wagl argumentu patrystyoznego, chociaz korzystał Juz z niego w sposób bardziej ograniczony. N1e stanowiz on wyraźnego źródła motywacjl wykładzle zagadnłeń teologłcznych 1 miał zdecydowanie mnjejsza wartośd stosunku do argumentu $x$ nauczania teologów czy Magisterium Kościoła ${ }^{2}$. Wywodzacy sie z zakonu Jezuitów, Tomasz Młodzlanowsk1/1622-1686/w odwołan1u s1o do "patres" widziat wprawdzie wystarczajacy argument potwierdzajacy jego poglądy, ale doktryna moralna 0jców Kościoła stanowiła prawie niewldoozny elenent w porównaniu do nawazu treśc1 soholastycznyoh. Teologla moralna Lzodz1anowskiego nle jest oparta o dobrze rozumlana 1 poznana nauke 0jó́w Kośctoła $a^{3}$.

1 Por. W. Wicher, X.Szymon Stanlsław Nakowsk1 teolog moral1sta polsk1 z XVII w., Kielce 1926, 155-160.

2 Por. J.Bereziński, Adam z Opatowa teolog moral1sta XVII wieku, Lubiin 1977, 158-167/mpsBKUL/.

3 Por. F. Greniuk, Tomasz Mkodzlanowsk1 teolog-moralista, Lublin $1974,144-145$. 
Takte róźnice $w$ podejściu do waloru argumentacyjnego nauki ojeów Kościoła w wykładzle teologicznym, a takze i teologiczno-moralnym są w pewnym sensie typone dla okresu usamodzielntanta sie poszczególnych dyscyplin, a zwłaszcza teologil moralnej. Proces ten dokonuje sie polsce z pernym opóntenten, podczas gdy na zachodzie jego poczįtki datuje sie od publikacjl "Institutiones morales" Jana Azora /I-III Roma 1600-1611/. W Polsce wolniej dochodziła do głosu śrjadomość najnowszych osiłjnięć nauk teologicznych, 1ch rozwoju w zakresie metodologiczno-formalnym.

W kontekście wspomnlanych wyżej przedstariciel1 polskiej nysl1 teologiczno-moralnej nie mozna pominąć dominikanina Mikozaja z Mośclsk4, którego dzieła teologlczno stanowlił rómniez waźny etap rozwoju teologli moralnej $w$ Polsce. Interesujace rydaje się zatem spojrzente na nle pod katem rykorzystanta dzieł 1 nauki Ofców Kościoła.

Argument z Tradycj1, a dokładnłej mówląc z ojców Kościoła,traktowany jest przez Mikołaja z Mościsk marginalnie 1 służy faktycznie tylko jako "dicta probantia". Wydaje sie navet, iz dominikańsk teolog nie uświadamia sobie nawet znaczenia argumentacjt z tego \&ródła. Jeślt juź powozuje s1a na ojeón Koscloła, to nie wy-

4 Mikołaj z Mośc1sk ur. 5 VIII 1559 r. W Mosciskach, V 1575 r. złozyl śluby zakonne u dominikanow in Krakowie. Po odbyciu studion w Kraliowie 1 Bolonil uzyskat w krakowskim studium generalnym w $1592 \mathrm{r}$. bakalaureat, zaś w $1594 \mathrm{r}$. doktorat, a nastepnie wykładał kazuistyke w Irrakowle, gdzte takze w latach 1596-1603 był rektorem. Był wspózałozycielem klasztoru "Na Gródku" w Krakowio oraz w Socheczewie. W plerwszym z nich oraz u norbertanek zwierzynleckich by przez wiele lat klexowntklem duchorym. Byz przeorem w Sandorierzu, Bochn1 i Płocku, a taike wikariuszem kontraty mazorieckiej. Dzlałal w bractile rózańcoiym w Krakowie oraz był kaznodzieja generalnym we Lwowle. Zmart W Krakow1 6 VI 1632 r. Na temat ogolnych danych o Mikołaju z Mościsk oraz Jego dorobku plsarsk1m por., np. J.Kowalsk1, Zycie, działalność 1 spuścizna pisarska dominikanina Mikokaja z Moscisk/1559-1632/, CzST 4/1976/ 147-164; W. W1cher, Mikołaj $z$ Mós 1sic, Lwow 1928; A.F.Dz1uba, Zyc1e 1 trórczość Mikotaja z Mościsk/1559-1632/, STv 19/1981/ 43-

Interesujace nas jego dzleła: Theologia moralis in treg 11bros distincta, videlicet in: I Elementa ad S.Confessiones, pp. 1-198/cyt.: Blomenta, II Sacrae Artis Poenitentiariae Tyrocinium, pp. 1-332/cyt.: Sacrae/, III Examen approbandorum ad sacras Confessiones exclpiendas, pp. 1-204/cyt.: Exanen/; Supplementum do matrimonio, pp.1-94, Cracoviae 1683; Elementarzyk éficzenia duchomnogo, Krakbw 1626; Akudemia poboznosic1. Nie tylko zakonnym osobom do doskonałości potrzebna ale y śwleckin do zbawienia barzo przygodna. lozdziolona na ploc Klasses abo $\mathrm{S}_{z k o k} 1$ ako pokaze Regestr przed samif rzocza polozony, Kr ków 1628. 
korzystuje zawartych tam mý́ll wosób pełny, traktuje je raczej tylko jako przykłady ozy uzupełnienia argumentacji opartej na autorytecie teologów czy w mniejszym stopniu Magisterium Kościoła. Mikołaj z Mościsk nie przeprowadza szczegółowych anal1z, jak to np. czynit nieco późniejszy Szymon Stanisław Makowski, nie móriąo juz - Inspiracji biblijnej wykładu teologil moralnej. Odwołymanie sie do Ojoów Kościoła pozostaje laktem jednostkowym, bez lototnego тpływu na bleg anallz scholastycznyoh.

W całości dzieł teologiczno-moralnych tylko jeden raz przy omawianiu kwest11 wiedzy spowiednika Mikołaj z Mościsk podkreśla wartość dokumont $\delta$ patrystycznych w sensie ogólnej nauki Kośc1o$\mathrm{a}^{5}$. Wykorzystywante cytatów z 0jców Kośc1oła jest bardzo ograntczone. Choć sa one dobrane odpowiednio do omawianogo zagadnienia, nie maja jednak lototnego wpływu na samo jego rozwiłzanie. Nie sa analizoirane $w$ pełni a najczesiciej pozostaja same dla siebie, bez jednoznacznego ustosunkowania sie do nich. Omaviajac zagadnienie grzechów przeciw dzlełom milosierdzia powołuje gie on na św.Augustyna piszac: "Delnde illud omnes meminisse debent, quod S.August: Ser. 45. ad eratres in Eremo dicit: Non meminl me legisse, allquem malo mortuum fuisse, qui vivens opera pietatis bene exercuerit" ${ }^{6}$. Brak natomiast blizszego rozwinlecia tej mý́li, jej bardziej praktycznych aplikacjl teologleznych czy nawet moralnych.

Bardzo rzadko Mikołaj z Mościsk posługuje się argumentem czy raczej przykładem kilku ojców równocześnje, przez zwyczajne wymienjente tylko ich $1 \mathrm{~m} 1$ on 1 ub $1 \mathrm{ch}$ dziel. Ten dość popularny wówczas sposób wzmacnianla argumentów teologicznych wystepuje tylko jeden raz, 1 to w kwestil "Fascinatio quid significat: an detur, et quomodo curetur?" gdy "pisze w odpowiedz1: "Caeterum al11 constant18simo negant. Inter quos Abulensis Sup: q. 18. sic ait: Nos quoque oum tota Ecclesia fascinationem Improbamus. Fandem damat Basllius, Chrysostomus, Hieronymus" ${ }^{7}$. W klikunastu miejscach spötyka s1e przyta-

5 Elementa, 55: "Hanc scientlam medicativam confossor ut acquirore possit, debet libros spirituales quotidie versare, documenta Patrum, Sanctorwa exempla in promptu habere atque in studio moditat1onis 1pse quoquemet assiduus esse".

6 Sacrae, 167 .

7 Examen, 200. 
ozanie samych nazw1sk bez określenia tytułu dzieja czy owentualnie określenta cytatu, który autor mlał na myśl1 odwołując sie do danego 0jca Kośo1oła ${ }^{8}$. Być może, lz ten sposób pochodzi z sleganta nie do bezpośrednich tekstów, lecz do osobistego, utrwalonego w dýslach bogactwa wiedzy patrystycznej. Swiadczyć o tym moze, np. bardzo ozeste 1 swobodne odwoływanta ate do ojców Kościoła w pismach ascetyozno-mistycznych.

Ostatecznie wroch dziełach /raczej czterech/teologicznomoralnych na przestrzent prawie 800 stron druku mozna doliczyd się tylko 24 cytat6w ozy bardziej ozytelnych odntesień do 0jó́w Kośc1o2a. Jest to bardzo nieviele 1 wystaria odpowiednte świadectro bazle źrólowej prezentowanej nauki.

Wyraźny cytat występuje tylko jeden raz 1 pochodz1 on, jak plsze autor z 45 mowy św. Augustyna ${ }^{9}$. Natomiast określenle tytuku dzieła danego Ojca, z którego Mikołaj z Mościsk zaczerpnął myśl, oznaczone jest 8 mlejscach ${ }^{10}$. W tym ostatnim przypadku wystepuja bardzo zróznicowane sposoby opisu bibllograpicznego, jeśl1 - takim mozna mówić.

Mając na uwadze ten fakt trudno wydać osąd co do stopnia streszczania poszczególnych teistóm, ozy wreszcle 1ch przeinaczania, lub też tworzenia wasnych parafraz. Wydaje sle jednak, 1z doskona-

8 Por. Elementa, 1: "Peocatum est/ut inquit S.Augustin/ dictum aut factum aut concupitum contra legem aeternam. Lex autem aeterna, ut 1 dem $D$. August. docet, est summa ratio oul semper obtemperandum est"; tamze 44: "Unde confessor sat1sfactionem prudenter debeat semper moderarl et temperare habita ratione personarum. occupationum, Infirmitatum, et potius de misericordia de Chrysostomo qua de lustitia velle ludicari"; Sacrae, 14: "Peccatum /quae est materia poenitentiae/ a D.Aug. sic describitur: Peccatum est dictum vel factum vel concupitum contra legem aeternam"; tamze 114: "aversio a bono divino, quae a D.Gregorio per antomasiom malit1a dicitur..."; tamze 242: "Ex Ind 1scret is racerationibus, lentunits, vigilits, ac recitationibus seu decantationibus Psalmorum vei of 1 iciorum per quas/ut D.IIferon: Insinuat/amentiae, melancholiae seu tristitiae nota incurritur ot rationalis hominis dignitas aidttiturn; Examen, 156: "Munus a manu/secundum D.Gregorium/ est peccunia et omne donum, quod 1ntuitu obtinend spiritualo datur"; tamze 172: "Addicitq. D. Ambr: testimonium. Vide 81 vis Conc.Trid: 8.21. c.5 de refor";
por. notg 7 .

9 Sacrae, 167; por. note 6.

10 Por. Sacrae, 53,56,76,196,255,277; Examen, $20,165$. 
ze przygotowanic naukowe Mikołaja z Mośc1sk pozwalało mu na swobodne poruszanle sie $w$ gąszczu patrystyk1, czego dowodem moga byó wsponniane wyżej dzleła ascetyczno-mistyczne.

17 zakresie częstotliwoścl odwoływania się do poszezególnych ojców Kościoła zdecydowany prym wiedzie ś. Augustyn, którego dom1n1karisi moralista wyulenta 9 razy. Sw.Grzegorz Wielk1 wykorzystany jest 5 razy, św.Jan Chryzostom 3 razy 1 św.Hieronfm 2 razy. Po Jednym razie odwołuje sliz do św.Leona Wielklego, św.Bazylego, ́́n.Jana Kasjana, św.Jana Damasceńskıego 1 św.Ambrozego. W przy padku śm.Jana Damascexiskiego chodzi o jego znane "regulam a S.Damascenon11. Widać więc w stopniu dość równorzędnym sleganie do myśl1 zarówno zachodniej, jak 1 wschodniej. Powozywanie sie na autorytet ojob́ Kosclola, a takzo autorytet biblifny, jezelichodzi o dzieła teologiczno-moralne występuje najczęsciej "Sacrae Art1s/s10/ poenitent1ariae tyrociniım" stanoriacyin podrecznik dla poczatkujacych spowiodnikow z dość duźym materiałem ściśle teologicznym.

Chc̨̧c zaznaczyć powoływanie sle na naukę 0jców Koścloła N1kołaj z Mościsk stosuje bardzo różne formy skrбtów oparte zazwyozaj na Imlonach łacińskich. Na przykład przy ́́w. Augustynie posługuje sle następującym1: "D. Aug"12, "Aug."13, "S. Augustinus n11, "D. August."15, "S. Augustin"16, "S. August."17. Warto zaurazyc, zo to rónnorodne skróty występuja niekiedy w jednym dzielo 1 to w niezbyt odlegzych od siebie miejscach. Istnieje jednak takze mato prawdopodobna mozliwośc, iz powstały one na skutek błędów drukarskich.

W wypadku podawanla z kolel tytułów dziel, dominikański moralista talsze posługuje sie skrótami bardziej lub mniej rozbudowanymi, co oczywiścio czasem ułatwia, a znacznie częsciej utrudnia, identyełkacje poszczególnych tekstóv. Jezell chodz1 o św.Augustyna, autor

11 Sacrae, 196: "Iuxta vero "Megulam a S.Damasceno celebratam". Quod Deus semel assumpsit, numquam dimisit".

12 Examen, 20; Sacrae, 14,53.

13 Sacrae, 76.

14 Tanże 114.

15 Elenenta, 1; Sacrae, 274.

16 Elenenta, 1.

17 Sacrae, 167 . 
trzykrotnie określa dokzadnie zaczerpnięte teksty. W tytule drugim, kwest11 ósmej "Examen approbandorum ad Confessiones exc1piendas ot ad parochias obtinendas" plsze: "Tum quia D. Aug: in Enchyrid: c.8. dicit" 18 . Natomiast "Sacrae artis poenitentiariae tyrocinium" wyraza sle: "Extra ludiclum, dio1tur mendacium, quod est verbum falsum, cum intentione fallend1: ex D. Aug. Relat1o, 2. 2. q. 2. Beatus"19 1 kilkanaścte stron dalej: "Quod tales conelgunt Deum, malodicti sunt in penuria, sterilitato, et al1is plagis. Aud: 11b.: 56 . hom. $48^{20}$. Takze przy tekstach św. Jana Chryzostoma 1 św. Grzegorza Wielklogo 22 Mikołaj z Mosolsk podaje dość dokładny op1s bibliograIiczny.

Najozęśclej jednak autor domintkański oplerając sie na danym autorytecle patrystycanym uzywa ogolnych sformulowań informacyjnych. Np. referujac zagadniente defintejt grzechu powołuje sie na św.Augustyna sposób ogólny: "Peccatum est, /ut inquit S.Augustin./ dictum $/ \ldots /^{23}$. Oczywície takze 7 otosunku do Innych Ojców Kościoła stosuJo podobny sposób powolywan1a s1e na loh autorytet teologiczny, h1storyozny ozy prawniczy ${ }^{4}$. W tradycj1 teologloznef bylo dośc powszechnle przyjete tak ogólne odwoływanie sle do patrystyk1. Wystarozat autorytet samego naziriska, którego waga była juz powszechnie znana. Szczeźlowe odwolywanie sie byłoby pewnym sensie zbednym truizmem a moze nawet pomiejszentem samego autorytetu.

Przy tak znikomym wykorzystanlu argumentu patrystyoznego nio mozna jednoznacznie rozstrzygná czy polski dominikanin posługuje sie oryginalnymi dzlezaril ojców Kościoła, cuy tez raczej a katenami

18 Examen, 20.

19 Sacrae, 53.

20 Tanze 76.

21 Tanze 277: "HIno Chrysostomus relatus C. Talis de Poen1t: d.3."

22 Tamie 255: "Secundum dictum est S.Greg: relatum dist. 5. cap:

23 Elementa, 1; por. Sacrae, 14: "Peccatum/quae est materia poen1tentlae/ a D.Aug. sic desoribitur"; tamzo, 114: "Quia S.Augustinus
docet". 24 Por. Bxamen, 46: "Num ut S.Leo dio1t"; tanze 114: "Mlanus a manu
pocundum D.Gregorlum est pecunda". 
1 florileglami, stanowiacyni zbiory cytatów z ojcón 1 p1sarzy starożytności chrześcijańskiej. Te swoiste wypley były w owym czasie bardzo popularne 1 chętnie z nich korzystano. Niekiedy prowadzilo to do smtesznych sytuacj1. Po prostu brak znajomoścl kontekstu, brak pełnych cytat $6 w$, powodował $1 \mathrm{ch}$ mnlejeza operatywnó́ć, a czasem wrącz nie pasowały one do danego problemu teologicznego. Nie ulega matpliwośc1, ze kateny sa bardzo dobrze znane Mikołajow1 z Mościsk ; 7 "Examen approbandorum ad confessiones" niemal na kazdej stronie powozuje sie na słynne "Clavia regla sacerdotum casuum consolentiae sive theologiae moralis thesauri locos omnes aperiens" Grzegorza Sayrusa $/+1602 / 25$. Teologiezno-moralne dzlexo Sayrusa, choć nie jest katena sensu strieto, podaje na początu kazdej ksiegi obfita literature patrystyczna. Wydaje s1e, ze spełnlało ono podobna role jak k1lkadzieslazt lat później w twórczoścl Sz.S.Makowskiego ${ }^{26}$.

Mikołaj z Mościsk znawoa Jezyka lacínskiego 1 greckiego, a moze także 1 hebrajskiego, z pewnosola ulegax tendencj1 swego okresu, wykorzystywanta oryginałow dzlez patrystycznych oraz wasnych przokładów Pisina św. Predysponowany z pewnośc1a, jeślt wprost nie korzystaz, to posrodnio czytał na etaple przygotowawczym $w$ oryglnalo dzleła ojców Kośc1 oła.

W korzystaniu z patrystyk1 nio mozna zauwazy biblijnej ojcór Kośojoła na interpretacje tekstów biblijnyoh, Jak to będzio mieć ntejsce, np. u Sz.S.Makowskiego. Dorobek patrystyk1 w tym wzglegcle jest przeciez szczególnie cenny 1 atanowié będzie lstotny ciement powrotu do Blblil w czasach póniejszych.

Dla lepszego usypuklenta roll argumentu patrystycznego $w$ twórczości teologlcznej Mikołaja z Mościsk warto jeszcze zwróclé uwage na grupe prac ascetyczno-mistyoznych, w któryoh bardzo obficle go wykorzystywat, w przeciwieństwio do dzlex teologiczno-moralnyoh, Na ok. 1200 stronach druku odmozywaz 818 on ok. 620 razy do dziel 34 Ojców Kościoła 1 pisarzy starożytnośc1 chrześcijańskiej. Nikołaj z Lośclsk bardzo rzadko powołuje sle wich na ogólnz oplnte ojcó

25 Por. Examen, 20,22,25,27 1 wiele 1nnych.

26 Por. W. Wichor, X.Szymon Stantsław Makousk1, dz.cyt., 28. 
Kosicioła, przewaznie cytuje tylko konkretne nazwiska ojców czy Doktorów Kościola powszechnego. Dzicła ascetyczno-mistyczne naplsaz on w jezyku polskim. Ponlewaz w tym czasie byzo jeszcze bardzo nie-

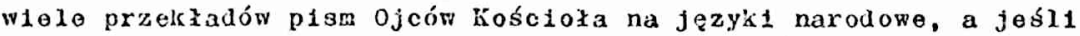
by ty to przeważle na lactre, autor nasz przy opracowywantu tych dzieł korzystał przeránie, jak się wydaje, z oryginałór lub róznego rodzaju katen dokonu,jac z nich, jak to zatwo można zauwaźc, wlasnego trumaczenta.

Ojcowie Kośc1oła służa Młkołajow z Mośc1sk w odczytywaniu sensu, Jaik 1 zawierać mogr poszczególne wyrazy, zdania 1 fakty b1blijne. Szczególna pomocą słuzą mu przede wszystkim św.Jan Chryzostom ${ }^{27}$, św.Hterontm 1 oczywiście jak w dzlezach teologicznomoralnych św. Augustyn ${ }^{29}$. Mniej natomiast powozuje się na plsarzy chrzośc1jaúsk1ch,np. orygenesa i Bedę Czciśodnego 30 . Caasem writka-

Por. Elementarzyk ériczen1a duchornego, Krakós 1626, 441:

"Uczófwie le/rellkwie/ tedy przylawszy y na otiarzal forozyvszy

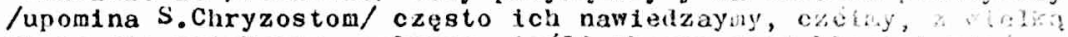
wlara sie uclekaymy, całuymy, lésil chceny stied blogostovieristwo y dobrodzloystwo otrzymać"; tamze, 178: "Cierpiiwośc nas przyrónnywa do Męczenników, Chryzostom S. nóvi"; Akuleria noboznośct, Krak6w 1628, 429: "Pantenstivo ludzy polobne czynt Anyozom y owszom ponlekad wietczne/tako Chryzostom śriladezy/s bo Anyolowie ciala nie maise moyny zadney cielesney nie doznali".

28 Elementarzyk, 311: "Idz1e nan o to, lakłchby pośrzodków zażyé na to umartwiento. Plersza lest, Rozmlyować siz rorazco Pana Boga: zapalí sio pragnieniem do rzeczy duchowych y niebieskich, otrzassąwszy siz z niedbalstwa około zbawionia swego, chąc konlecznie koło niego chodzlć, wiఠo y pokolu swym wnętrznyı zakochaó sia. To natrąca Swięty Hieronin?; tamie 478: "Tác to cierpliwościa gwatt sie ozyni niebu/mówi S.H1eronim/"/.

29 Elementarzyk, 311: "Augustyn Swiety pieknie o tym mówi: Ząazom clolesnyo nie post ̨pować, nie zezwalać, wielka chwała jest; a nie mied ich doskonałość"; tanze, 478: "0 cierplitrośc//mów1 Augustyn S./. te mszystk1e przociwnośc1 zwyolęzysz, nie spólnte s1a modlįc, ale znoszłc, nio ozenrząc ale dziękujac. Cierpliwość prace, boleścl y choroby ul tyna y znośne czynt, laiko ntec1erpliwośc dodale bólu, lz clezszy sie zda. Bo lako Augustyn s. mów 1: "Dum pat1 repugnat non se liberat a malis, sed ea sib1 facit graviora"... Cierpliwość /powiada Augustyn S./ piokielne drzwi zanyka, niebieskie otwieran.

30 Por. Ellementarzyk, 181: "Akadem1a poboznośc1, 96, 124. 
Jąc w treśc Słowa Bożego zawartego na kartach Pisma św. dodaje, ze myślf. przez niego wyprowadzone sa powszechnym zdantem patrysty$k^{31}$. Te generalne uwagl pozwalaja mu na pypowtedzente bardziej ogólnych sçáw teologlcznych, 1 to wiazzacych w pezniejszym sensio.

Przytaczana argumentacja z 0jcór Kościoła bardzo często nie posiada blizszych danych dotyczacych tytułu dzteła, rozdziału czy strony cytatu lub opisu. Brais więc opisu blbllograficznego w sensle najbardziej generalnym ${ }^{32}$. Moze to dowodzić, Jak wspomniano wyzej, cytoranta przez Mlkozaja z Mościsk z pamięc1 poszczególnyoh autorów, których był doskonazym znarca. Mozliwe jest takze, iż teksty te byzy povszechnie znano 1 przyjmowane za oczywiste przez ówczesnych teologóv 1 pisarzy chrześcijańskich. Hisystko to stwarza niebezpleczeństwo nleścisłosci oraz znacznie utrudnia weryeikacje w oryglnaźach przytaczanych myśl1.

Dla poznego obrazu argumentacj1 patrystycznej w pismach ascotyozno-intstycznych warto jeszcze podać dano o częstotliwości /w nawiasech/ odwoływania sie przez Mikołaja z Mośc1sk do poszczególnych ojców Kościoła czy teź pisarzy starozytności chrześcijańskiej, wśród

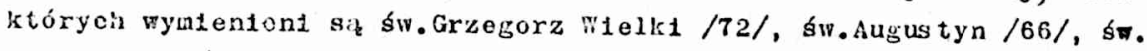
Jan Kasjan /58/, św.llteronim /51/, św.Bazyl1 /50/, św.Jan Chryzostom $/ 37 /$, sw.Ambrozy /33/, św. Eerem Syryjsk1 /18/, św.Cezary z Arles /17/, św.Cypxian /16/, św.Grzegorz z Nyssy /16/, św.Doroteusz /15/.

31 Ejomentir $x y k$, 322: "Tak to umartwiente potrzebne jest do doskonałosci, Oycowie SS. piszac na one słowa luk 19 twierdzą, ze kto nde dostigl wyrzeczonia abo zaprzenta sie swey wold, abo sie o nie nie stara, popróźnicy dobra ziemskle wzgardzí y udał sie do życia Zakonnego".

32 Por. Elementarzyk, 1: "Nawlecey m1 się podoba oplsanie Modlitwy podane przez S. Grzegorza Nisseńskiego, bo lest tak zaćne, ze iszolkiey modiltwy wyraza wasnośc"; tamż, 18: "Mówi Cassianus - tye, liz lako każde rzontosło potrzebuje Ástrza, tak tez/y owszera daleiso wiecey/ ćwlezenie duchowne"... Czytamy u Sofroniusza o jednym justelniku tak św1 miał... S. Sicty dugustyn tak mów1: Ja stary tak dawno będac b1skupea gotowem sie dać nauczyć młodemu i rocznemu koledze. S.Chryzostom laówi, ze Moyzesz Swiety, uczony nie mógl sie dunysil zlecíc lnnyw sprairy to sazdu, aże mu poganin poradziz Yetro ociec zony 1ego"; traze, 237: "I dlatego Shigty Grzegorz mów1, Co jest pismo bwlate, ledno nielak1 jist Boga wrzechrogacego do stworzenta swego"; por. Akademia poboznośc1, $8,15,20$. 
Pontzej 10 razy odwołuje sie do następujących ojców: św. Izydora z Sewill1 /9/, św. Grzegorza z Nazjanzu /8/, św.Bedy Czc1godnego /7/, św.Leona Wlelkiego /7/, św.Paulina $/ 7 /$, św.Jana Damasceńskiego /6/, św.N1la /5/, śn.Grzegorza Cudotwórcy /4/, św. Rufina /4/, Éw.Klemensa papieza $/ 4 /$, św.H1larego /3/, ś.Atanazego /3/, św.Grzegorza Turyńskiego $/ 2 /$, św. Pachomiusza $/ 2 /$. Warto dodać, te Mikolaj z Mościsk korzysta z dzlez starochrzéscijáskich pisarzy nie zaliczanych do 0jcón Kościoła: Jana Klimaka $/ 27 /$, Orygenesa $/ 14 /$, Pseudo-Dionizego Areopagity $/ 4 /$, Teodoreta /3/, Klemensa Aleksandryjaklego / $/$.

Wydaje sio, it nawet taki zestaw cyfr 1 nazwisk w kontekście plsm teologiczno-moralnych Mikołaja z Mościsk mów1 bardzo wiele. Jakze 1nny,w Polsce, by $z$ chemat redagowania pism waleznośl od 1 ch przeznaozenia: do kapłanów czy dla ludzi éwleckich lub téz zakonnic. Ocentając ogólnie argumentacje patrystyczna wismach teologiczno-moralnych Mikojaja z Mościok nalezy stwierdzió, ze jest ona traktowana bardzo marglnalnie w preciwieństwie do dzlez ascetyczno-mistycznych, które sa nia nasycone ${ }^{33}$. Ostatecznie bowiem, podobnie jak 1 przy Piśmie św., treśó doktryny moralnej 0jców Kościoła nie stanowi dla niego szczególnego przedmlotu zainteresowania, a argumentacja z nief czerpana stanowi prawie nlewidoczny element porbwnaniu do nawaku treści soholastycznych, wtórych odwołuje s1e bardzo czesto do autorytetu teologów, a rzadzlej na Magisterium Kościoła, zwłaszcza nauke Soboru Trydenckiego. Nawet sporadycznie mystępujace odwołania się do nauk1 0jeów Koścloła nie sa pełni wykorzystane, nie stanowia lnspiracji 1 źródła podstawowych pogladów teologleznomoralnych.

Oczywí́cie, podobnie jak brak Plema f́w., tak 1 brak argumentacj1 patrystycznej w dorobku teologiozno-moralnym Mikołaja z Mościsk jest ogromyin mankaisentem metodologiczno-forinalnym w zakresie zasad poznania teologioznego, tym bardziej, te wartość tego rodzaju argumentacj1 podnosito juz o wiole lat woześntej dzioło M.Cano "De locio theologic1s". Okres przelomu XVI 1 XVII stulecia, w którym zyl 1 działaz Níkolaj z Mośc1sk, cechowal sie postulatem powrotu do źródel. Były tym wz go 1 uozonych skupionych wokós Kolegium Rzyaskiego Jezuitów.

33 Por. J.Kowalsk 1, Nauka Likołaja z Mośc1sk o modlitw1o wewnętrznoj, Kraliów 1966, 249-250/aps - wasność autora/; tenżo, P1smo ám. " twórczości ascetycznej Mlikolaja Mośc1sk, KBL 20/1967/85-93. 
Ostatecznte brak argumentacj1 z Ojców Kościoła kresu teologit moralnej dominikańskiego toologa sprawik, ze sa one legalistyczne 1 mało pozytywne. Teologla moralna Mikolaja z Mościsk na pewno nie jest oparta na dobrze poznanej 1 rozumianej Tradyoj1 czy patrystyce. Takze 1 w tej płaszozyznte argumentacj1 toologicznej moral1sta z Kakowa okazal sig dzleckiem swojej epok1.

$$
\text { K8. Andrzej F. Dztuba - Warszawa }
$$

I PADII DELLA CHIESA

NELLE OPERE TEOLOGICO-MOLALI DI NICOLAO DA MOSCISKA /1559-1632/ /Riassunto/

L'Insegnamento della teologia morale, a parte gli element1 riguardant 1 contenut1, presenta pure precisi element1 metodologlco-formal1, Ira 1 quali 1 princlp1 della conosoonza, nonohè 1 argomentazione che ne scaturisce. Le opere teologico-morall d1 N1colaò da Mościska si inseriscono nella corrente generalo della teologia morale pratioata Ira 1 XVI/XVII seool1. L'autore utilizza poco la Sacra scrittura e 1 Padri della Chiesa. Queste fonti della conosconza in toologia moralo adempirono, nelle lezion1, 11 ruolo 1 "dicta probantia" e non svolsero 11 ruolo de element1 fondant1. N100laò da Mościaka nell'ambito dell'argonentazione mette in evidenza 1'autorità del teologi. Nonostante avesse presente 1 prínolp1 metodologic1 di $M$. Cano, di Erasmo da Hotterdam, del suocitati pionieri del rinnovamento, $i 1$ nostro autore non adopera quasi 1 loro postulat1 nell'insegnamento della toologla morale. In breve, o1roa prino1p1 /sopra tutto 1 padri della Chiesa/ della conosoenza della argomenti Nicolaò da Mosciska si dimostrò un figlio della sua opoca. 